\title{
Comparison of values in critically ill patients for global end-diastolic volume and extravascular lung water measured by transcardiopulmonary thermodilution: A metaanalysis of the literature
}

\author{
V. Eichhorn ${ }^{\mathrm{a}, *}$, M.S. Goepfert ${ }^{\mathrm{a}}$, C. Eulenburg ${ }^{\mathrm{b}}$, M.L.N.G. Malbrain ${ }^{\mathrm{c}}$, D.A. Reuter ${ }^{\mathrm{a}}$ \\ a Department of Anesthesiology, Center of Anesthesiology and Intensive Care Medicine, University Medical Center \\ Hamburg-Eppendorf, Martinistr. 52, 20246, Hamburg, Germany \\ b Department of Medical Biometry and Epidemiology, University Medical Center Hamburg-Eppendorf, Martinistr. 52, 20246, \\ Hamburg, Germany \\ c Intensive Care Unit, Ziekenhuis Netwerk Antwerpen, ZNA Stuivenberg, Lange Beeldekensstraat 267, B-2060 Antwerpen, Belgium
}

Received 6 September 2011; accepted 17 November 2011

Available online 28 January 2012

\author{
KEYWORDS \\ Hemodynamic \\ monitoring; \\ Preload; \\ Pulmonary edema; \\ Global end-diastolic \\ volume; \\ Extravascular lung \\ water
}

\begin{abstract}
Introduction: Hemodynamic parameters such as the global end-diastolic volume index (GEDVI) and extravascular lung water index (EVLWI), derived by transpulmonary thermodilution, have gained increasing interest for guiding fluid therapy in critically ill patients. The proposed normal values $\left(680-800 \mathrm{ml} / \mathrm{m}^{2}\right.$ for GEDVI and $3-7 \mathrm{ml} / \mathrm{kg}$ for EVLWI) are based on measurements in healthy individuals and on expert opinion, and are assumed to be suitable for all patients. We analyzed the published data for GEDVI and EVLWI, and investigated the differences between a cohort of septic patients (SEP) and patients undergoing major surgery (SURG), respectively. Methods: A PubMed literature search for GEDVI, EVLWI or transcardiopulmonary single/double indicator thermodilution was carried out, covering the period from 1990 to 2010.

Intervention: Meta-regression analysis was performed to identify any differences between the surgical (SURG) and non-surgical septic groups (SEP).

Results: Data from 1925 patients corresponding to 64 studies were included. On comparing both groups, mean GEDVI was significantly higher by $94 \mathrm{ml} / \mathrm{m}^{2}(95 \% \mathrm{Cl}$ : [54; 134]) in SEP compared to SURG patients $\left(788 \mathrm{ml} / \mathrm{m}^{2}\right.$ 95\% Cl: [762; 816], vs. $694 \mathrm{ml} / \mathrm{m}^{2}, 95 \% \mathrm{Cl}$ : [678; 711], $\left.p<0.001\right)$. Mean EVLWI also differed significantly by $3.3 \mathrm{ml} / \mathrm{kg}(95 \% \mathrm{Cl}$ : [1.4; 5.2$]$, SURG $7.2 \mathrm{ml} / \mathrm{kg}, 95 \% \mathrm{Cl}$ : [6.9; 7.6] vs. SEP $11.0 \mathrm{ml} / \mathrm{kg}, 95 \% \mathrm{Cl}:$ [9.1; 13.0], $p=0.001)$.
\end{abstract}

\footnotetext{
* Corresponding author.

E-mail address: volkereichhorn@yahoo.com (V. Eichhorn).
} 
Conclusions: The published data for GEDVI and EVLWI are heterogeneous, particularly in critically ill patients, and often exceed the proposed normal values derived from healthy individuals. In the group of septic patients, GEDVI and EVLWI were significantly higher than in the group of patients undergoing major surgery. This points to the need for defining different therapeutic targets for different patient populations.

(c) 2011 Elsevier España, S.L. and SEMICYUC. All rights reserved.

\section{PALABRAS CLAVE \\ Monitorización hemodinámica; Precarga; Edema pulmonar; Volumen diastólico final global; Agua pulmonar extravascular}

\section{Comparación de valores del volumen diastólico final global y el algua pulmonar extravascular, medidos mediante termodilución transcardiopulmonar en pacientes críticamente enfermos: metaanálisis bibliográfico}

\begin{abstract}
Resumen
Introducción: Parámetros hemodinámicos como el índice de volumen diastólico final global (GEDVI) y el índice de agua pulmonar extravascular (EVLWI), obtenidos mediante termodilución transpulmonar, suscitan un interés creciente como guía de la terapia de fluidos en pacientes críticamente enfermos. Los valores normales propuestos $\left(680-800 \mathrm{ml} / \mathrm{m}^{2}\right.$ para el GEDVI y 3 $7 \mathrm{ml} / \mathrm{kg}$ para el EVLWI) se basan en mediciones realizadas a individuos sanos y en la opinión de expertos, y se asume que son adecuados para todos los pacientes. Analizamos los datos publicados sobre el GEDVI y el EVLWI e investigamos las diferencias entre una cohorte de pacientes septicémicos (SEP) y pacientes sometidos a cirugía mayor (SURG) respectivamente.

Métodos: Se realizó una búsqueda bibliográfica en PubMed de GEDVI, EVLWI o termodilución trasncardiopulmonar de indicador único/doble referida al periodo comprendido entre 1990 y 2010.

Intervenciones: Se realizó un análisis de metarregresión para identificar las diferencias entre los grupos quirúrgico (SURG) y no quirúrgico septicémico (SEP).

Resultados: Se incluyeron los datos de 1925 pacientes correspondientes a 64 estudios. Al comparar ambos grupos, el GEDVI medio resultó ser significativamente mayor, con un aumento de $94 \mathrm{ml} / \mathrm{m}^{2}$ (IC del 95\%: [54; 134]) en el grupo SEP en comparación con los pacientes SURG $\left(788 \mathrm{ml} / \mathrm{m}^{2}\right.$, IC del 95\%: [762; 816], frente a $694 \mathrm{ml} / \mathrm{m}^{2}$, IC del 95\%: [678; 711], p<0,001). El EVLWI medio también presentó una diferencia significativa de $3,3 \mathrm{ml} / \mathrm{kg}$ (IC del $95 \%:[1,4 ; 5,2]$, SURG 7,2 ml/kg, IC del 95\%: [6,9; 7,6] frente a SEP 11,0 ml/kg, IC del 95\%: $[9,1 ; 13,0], p=0,001)$. Conclusiones: Los datos publicados del GEDVI y el EVLWI son heterogéneos, especialmente en pacientes críticamente enfermos, y a menudo superan los valores normales propuestos a partir de individuos sanos. En el grupo de pacientes septicémicos, los índices GEDVI y EVLWI fueron significativamente más altos que en el grupo de pacientes sometido a cirugía mayor. Esto pone de manifiesto la necesidad de definir distintos objetivos terapéuticos para las distintas poblaciones de sujetos.
\end{abstract}

(c) 2011 Elsevier España, S.L. y SEMICYUC. Todos los derechos reservados.

\section{Introduction}

There is increasing evidence that appropriate hemodynamic management is related to outcome in critically ill patients, both in the operating room and in the intensive care unit. ${ }^{1-3}$ Reliable assessment of cardiac preload, volume responsiveness, cardiac output (CO) and also indicators for potential fluid overload (extravascular lung water, EVLW) are prerequisites for successful management of hemodynamically unstable critically ill patients.

As well as imaging techniques, such as transesophageal echocardiography, thermodilution techniques, and in particular transcardiopulmonary thermodilution, allow accurate assessment of cardiac preload volumes by measuring GEDVI. ${ }^{4-6}$ For this assessment, cold saline as a freely diffusible indicator is injected randomly throughout the respiratory cycle via a central venous catheter. The mean transit time (MTT) and the exponential downslope time
(DST) of the thermal indicator are detected by a thermistor tipped catheter in the femoral artery (Figure 1). ITTV, the intrathoracic thermal volume, is calculated from $\mathrm{CO} \times$ MTT and the pulmonary thermal volume (PTV) is derived from CO $\times$ DST. GEDV is then calculated by subtracting PTV from ITTV (Figure 2). For inter-individual comparability GEDV is then indexed to the patients' body surface (GEDVI).

Hypovolemic patients with decreased cardiac preload present with lower values of GEDVI and are more likely to respond to a volume challenge with a significant increase in $\mathrm{CO}^{6}{ }^{6}$ Because of decreased invasiveness compared to pulmonary artery catheterization, and its greater operator-independency compared to echocardiography, the method has gained increasing acceptance over the last decade among physicians for determining cardiac output and preload and is made commercially available by Pulsion Medical Systems (Munich, Germany). ${ }^{7,8}$ Also available, the LiDCO plus uses lithium for calibration and provides a 


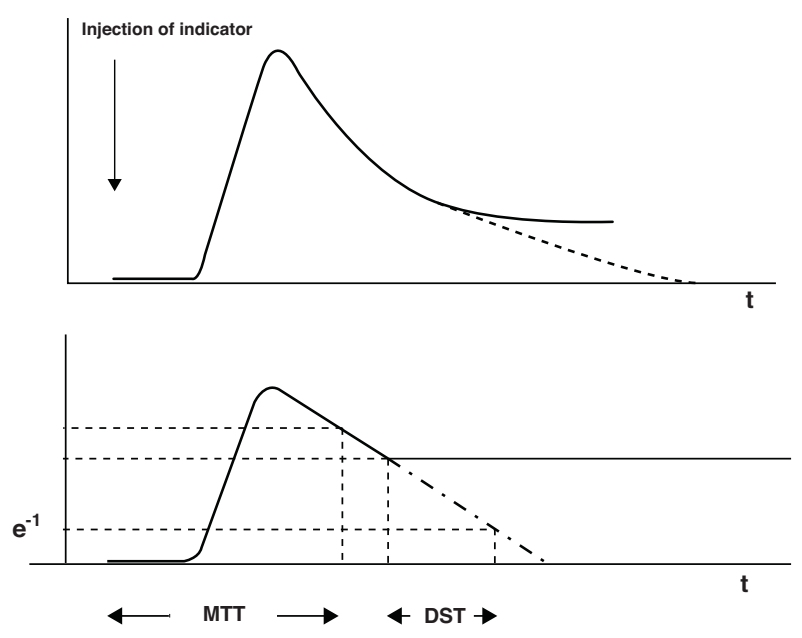

Figure 1 The upper curve indicates a thermodilution curve obtained by injection of a cold bolus, showing the temperature over time at the catheter tip. By extrapolation of the curve (dashed line), potential recirculation phenomena are excluded. The lower curve shows the logarithmic extrapolation allowing to define the mean transit time (MTT) and the exponential downslope time (DST) of the indicator.

reliable CO monitoring (LiDCO, Cambridge, UK). ${ }^{9}$ Recently, an alternative device (Volume-view, Edwards Life Sciences, Irvine, USA) using basically the same technical approach for measurement of GEDVI as the established PiCCO monitor $\left(\mathrm{PiCCO}_{2}\right.$, Pulsion Medical Systems, Munich, Germany), has been described as showing equivalent results in an animal model. ${ }^{10}$

Optimizing preload by volume loading may be limited by excessive fluid retention and the development of tissue edema, especially in the lungs. Here, the degree of tissue edema, i.e. the extravascular lung water (EVLWI), is difficult to quantify but is important information needed to guide therapy. ${ }^{11}$ Although chest X-ray is widely used to assess the grade of pulmonary edema, there is evidence that it is inadequate for determining fluid overload in the lungs. ${ }^{12}$ Furthermore the presence of pleural effusions must also be taken into account when interpreting EVLWI. ${ }^{13}$ Patroniti et al. demonstrated good correlation between lung edema and quantitative computed tomography, ${ }^{14}$ but this method is associated with high exposure to ionizing radiation and is not available at the bedside, excluding its use as a monitoring device. The EVLWI can be monitored and quantified by indicator dilution techniques and is calculated as the EVLW divided by the predicted body weight. ${ }^{15}$ EVLWI measured by single transcardiopulmonary thermodilution correlates well with the respective values measured by double indicator techniques ${ }^{16,17}$ and with human ${ }^{18}$ and experimental measurements by postmortem gravimetry, representing the experimental gold standard. ${ }^{19-21}$ Increased EVLWI is associated with poor outcome in critically ill patients. ${ }^{22-24}$ Furthermore, treatment of Acute Respiratory Distress Syndrome (ARDS) driven by EVLWI has been attributed as being beneficial for outcome in the critically ill. ${ }^{24,25}$

The use of both GEDVI and EVLWI has also been proposed in treatment algorithms. Their use has pointed towards improved outcome in cardiac surgery patients. ${ }^{26}$
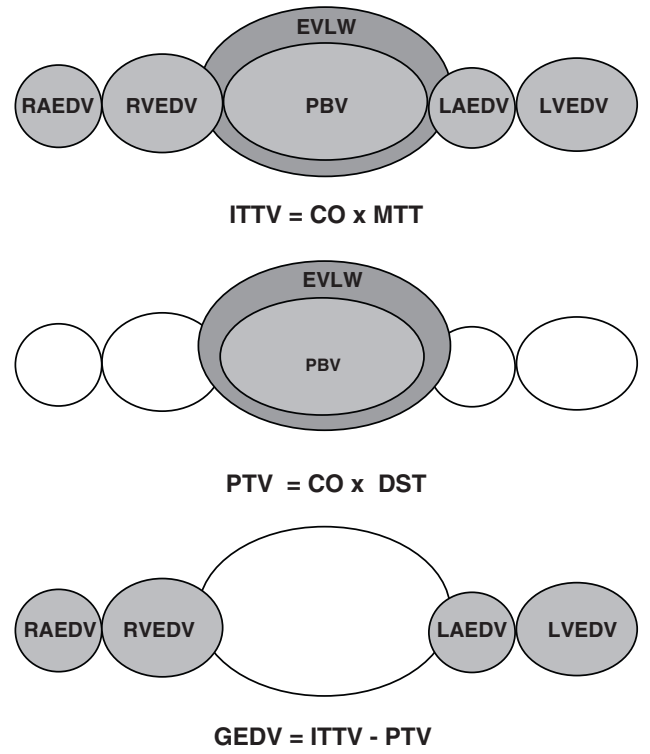

Figure 2 Assessment of global end-diastolic volume (GEDV) by transcardiopulmonary thermodilution. From top to bottom: first row: the intrathoracic thermal volume (ITTV) is the distribution volume of the thermal indicator, including the right atrium end-diastolic volume (RAEDV), the right ventricle (RVEDV), the pulmonary blood volume (PBV), the extravascular lung water (EVLW), the left atrium (LAEDV) and the left ventricle (LVEDV). It is calculated by multiplying cardiac output (CO) with the mean transit time $\left(M T t_{T}\right)$ of the indicator. Second row: the pulmonary thermal volume (PTV) includes the PBV and the EVLW and is assessed by multiplying $\mathrm{CO}$ with the exponential decay time $\left(D S_{T}\right)$ of the thermal indicator. Third row: the GEDV is calculated by subtracting PTV from ITTV.

This led to the inclusion of these parameters into the current treatment guidelines for postoperative cardiac surgery patients. ${ }^{27}$ The normal values for these parameters are given as $680-800 \mathrm{ml} / \mathrm{m}^{2}$ for GEDVI and 3-7 $\mathrm{ml} / \mathrm{kg}$ for EVLWI, which in turn serve as hemodynamic targets. ${ }^{26-28}$ However, these values are primarily based on initial measurements in healthy individuals and on expert opinion, regardless of patients' age.

Recently Wolf et al. showed a dependence of GEDV on age, gender, height and weight in a hemodynamically stable patient population, which remained even after indexing the parameter to body surface area. ${ }^{29}$ These data from noncritically ill patients demonstrate surprising heterogeneity of values. Tagami et al. recently defined a normal EVLWI of $7.3 \pm 3.3 \mathrm{ml} / \mathrm{kg}$ in a human autopsy study showing that the proposed normal values of $3-7 \mathrm{ml} / \mathrm{kg}$ are possibly not appropriate for most clinical scenarios. ${ }^{18}$ Additionally it needs to be considered whether these normal values are eligible for all patient groups. For example, differences may be found between critically ill patients suffering from various different diseases and, for instance, short stay surgical patients.

To our knowledge no systematic data analysis of GEDVI and EVLWI values exists between different patient cohorts. As a first step it was therefore necessary to identify the actual reported values of GEDVI and EVLWI in different critically ill populations and secondly to define reasonable treatment goals in these different patients groups. 


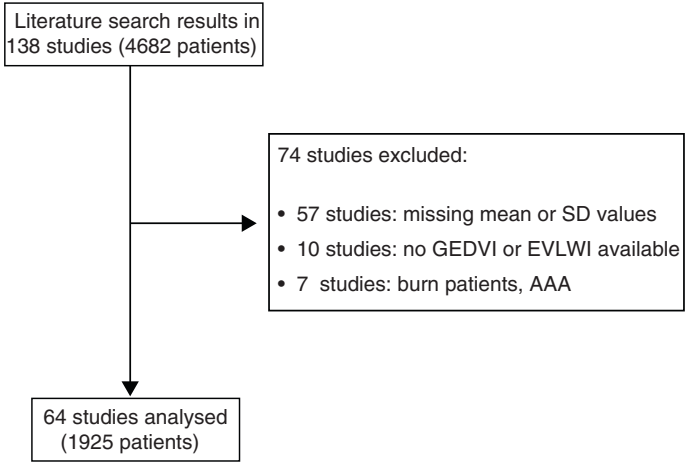

Figure 3 Flow of study inclusion. SD = standard deviation, GEDVI=global end-diastolic volume index, $E V L W I=$ extravascular lung water index, $A A A=$ aortic aneurysm repair including aortic clamping and axillary catheterization.

Therefore we performed a literature search of analyzed, published values for GEDVI and EVLWI in critically ill patients. The aim of our study was to analyze the ranges of published data on GEDVI and EVLWI in adult, critically ill patients, and to explore if differences existed between surgical and non-surgical (predominantly septic) patients.

\section{Materials and methods}

We searched PubMed from January 1990 to April 2010 using the search strategy "transpulmonary/transcardiopulmonary single/double indicator thermodilution" OR "global enddiastolic volume" OR "extravascular lung water". We restricted the search to studies in adults. Only articles published in English or German were considered. Further information was retrieved through a manual search of references from recent reviews and relevant published original studies.

The majority of included studies reported ITBVI instead of GEDVI. For comparability of all analyzed studies GEDVI was determined by calculating ITBVI/1.25, which has been shown to be accurate based on the linear relation between ITBVI and GEDVI. ${ }^{17}$ In total, 74 studies had to be excluded from the analysis (reasons given in Figure 3 ). The main reason for exclusion was incomplete data given by the study, such as missing mean or standard deviation values. Furthermore, severe burn patients were also excluded because they have massive capillary leakage and unique volume distribution leading to hypovolemia, and are therefore not comparable to either the surgical or septic patient groups. Patients undergoing aortic surgery were excluded because aortic malformations potentially result in abnormally high indicator distribution volumes. For the same reason studies that used catheterization sites other than the femoral artery were not considered. Furthermore, studies in pediatric patients were excluded.

Meta regression analysis was performed to estimate the difference between the surgical (SURG) and the non-surgical group (SEP), adjusting for heterogeneity within groups. ${ }^{30} \mathrm{All}$ statistical tests were conducted by using Stata 11.0 (StataCorp LP, TX, USA) with a level of significance of $5 \%$.

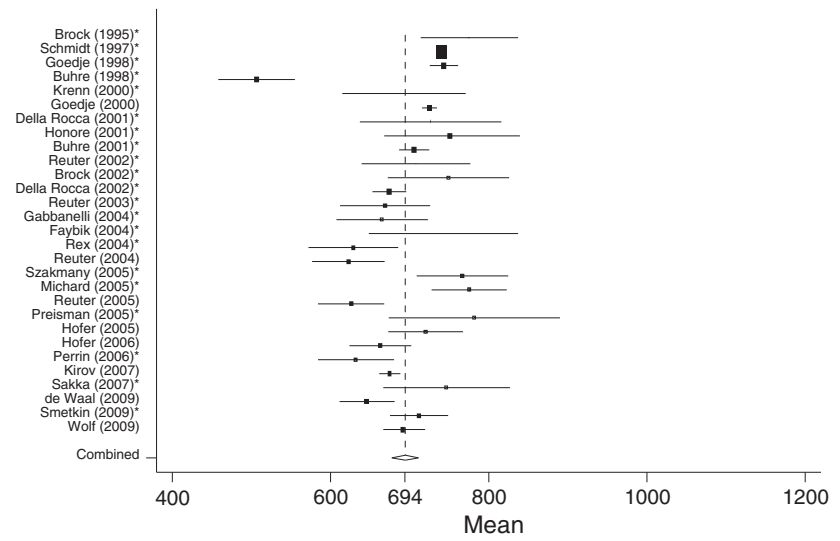

Figure 4 Forest plot of individual study results and pooled mean estimator from a random-effects meta analysis concerning GEDVI data in surgical patients (SURG). *Studies in which ITBVI was transformed to GEDVI (GEDVI = ITBVI/1.25).

\section{Results}

We found 138 articles that included a total of 4682 patients. Data from 1925 patients from 64 studies were included in the final analysis. The majority of patients in the surgical group had underdone cardiac surgery, but several other kinds of major surgery, e.g. abdominal surgery, neurosurgery, were also included in the SURG group. The studies included in the SEP group consisted of critically ill, mechanically ventilated patients predominantly treated for sepsis with accompanying acute lung injury.

Overall the patients showed a wide range of values. GEDVI varied from 378 to $1433 \mathrm{ml} / \mathrm{m}^{2}$ and EVLWI from 1 to $46.6 \mathrm{ml} / \mathrm{kg}$ respectively. After stratification of studies to either SURG or SEP, the groups were analyzed separately and then compared.

\section{GEDVI}

\section{Surgical patients (SURG)}

In the surgical group 37 studies with 1127 patients were identified. In total 29 studies including 867 patients fulfilled the inclusion criteria and were statistically analyzed. From the individual papers the lowest mean GEDVI was $506 \pm 78 \mathrm{ml} / \mathrm{m}^{231}$ and the highest mean GEDVI was $781 \pm 234 \mathrm{ml} / \mathrm{m}^{2}$ given in a study from Preisman et al., who performed stepwise volume loading in cardiac surgery patients. ${ }^{32}$ The pooled estimate for the mean value for GEDVI from all papers for the SURG group was $694 \mathrm{ml} / \mathrm{m}^{2}$, $95 \% \mathrm{Cl}$ : [677; 711], with the data being significantly heterogeneous $(Q=334.6, \mathrm{df}=28, p<0.001$, see Figure 4$)$.

\section{Non-surgical septic patients (SEP)}

The non-surgical patient group consisted of 701 patients included in 23 studies. Here the lowest mean was $667 \pm 177 \mathrm{ml} / \mathrm{m}^{233}$ and the highest mean GEDVI was $977 \pm 291 \mathrm{ml} / \mathrm{m}^{2} .{ }^{34}$ The pooled estimate for the mean value of GEDVI in the SEP group was $788 \mathrm{ml} / \mathrm{m}^{2}, 95 \% \mathrm{Cl}$ : $[761 ; 816]$; 


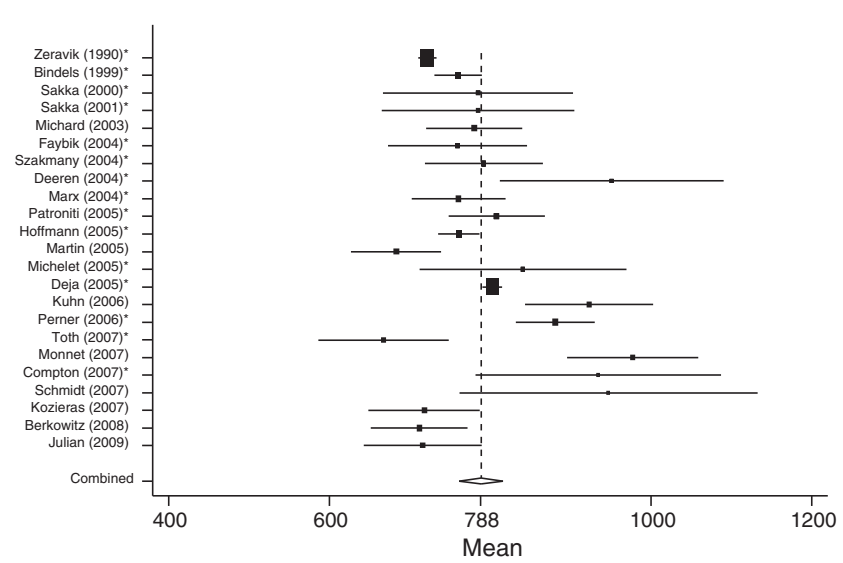

Figure 5 Forest plot of individual study results and pooled mean estimator from a random-effects meta analysis concerning GEDVI data in non-surgical patients (SEP). *Studies in which ITBVI was transformed to GEDVI (GEDVI = ITBVI/1.25).

with data here also significantly heterogeneous $(Q=194.7$, $\mathrm{df}=22, p<0.001$, Figure 5).

When comparing both groups the mean GEDVI was $94 \mathrm{ml} / \mathrm{m}^{2}$ (95\% Cl: [54; 134]) higher in patients from the SEP group compared to those in the SURG group $\left(788 \mathrm{ml} / \mathrm{m}^{2}\right.$ 95\%Cl: [762; 816], vs. $694 \mathrm{ml} / \mathrm{m}^{2}, 95 \% \mathrm{Cl}$ : [678; 711]). Despite the high heterogeneity of the data, statistically significant differences between the groups were found $(p<0.001)$.

In patients undergoing major surgery (SURG) 18 of 29 studies revealed GEDVI values within the given 'normal range' of $680-800 \mathrm{ml} / \mathrm{m}^{2}$. In non-surgical septic patients GEDVI was outside the proposed 'normal range' in 10 of the 23 studies: One study showed data below the lower limit of $680 \mathrm{ml} / \mathrm{m}^{2}$ and 9 studies described values above the upper limit of $800 \mathrm{ml} / \mathrm{m}^{2}$.

\section{EVLWI}

\section{Surgical patients (SURG)}

When analyzing EVLWI in the SURG group 19 studies including 687 patients were identified. The lowest mean EVLWI was $5.4 \pm 1.1 \mathrm{ml} / \mathrm{kg}$. ${ }^{35}$ The highest mean EVLWI was $10.6 \pm 4 \mathrm{ml} / \mathrm{kg}$ measured in patients undergoing lung resection. ${ }^{36}$ Here, the included post lung resection values might have led to high values. ${ }^{37,38}$ Nevertheless, these studies were included in the present analysis because of limited data proving clinical significance of this potential methodological error. The pooled estimate for the mean value of all studies in the surgical patient group was $7.3 \mathrm{ml} / \mathrm{kg}(95 \% \mathrm{Cl}$ : [6.8; 7.6]; heterogeneity: $Q=389.4$, $\mathrm{df}=18, p<0.001$, Figure 6).

\section{Non-surgical septic patients (SEP)}

In the SEP group 20 studies with a total of 598 patients were identified. From all studies the highest mean EVLWI was $21.4 \pm 10 \mathrm{ml} / \mathrm{kg}$ and the lowest mean was $5.2 \pm 0.5 \mathrm{ml} / \mathrm{kg}^{39}$ The overall pooled estimate for the mean value of EVLWI in the group of medical patients was $11 \mathrm{ml} / \mathrm{kg}, 95 \% \mathrm{Cl}$ :

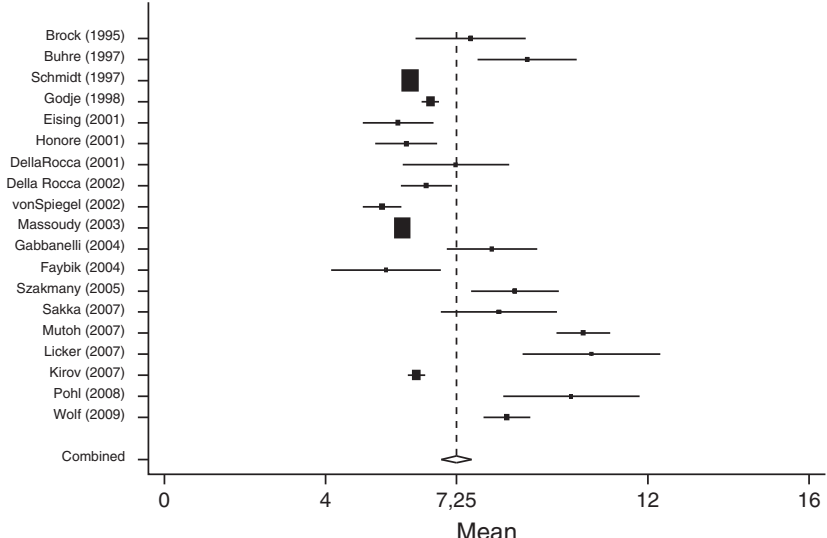

Figure 6 Forest plot of individual study results and pooled mean estimator from a random-effects meta analysis concerning EVLWI data in surgical patients (SURG).

[9.0; 13.0]; heterogeneity: $Q=2270.7, \mathrm{df}=19, \quad p<0.001$ (Figure 7)

When comparing both groups, mean EVLWI differed by $3.3 \mathrm{ml} / \mathrm{kg}$ (95\% Cl: [1.4; 5.2], SURG $7.3 \mathrm{ml} / \mathrm{kg}, 95 \% \mathrm{Cl}:[6.9$; 7.6] vs. SEP $11 \mathrm{ml} / \mathrm{kg}, 95 \% \mathrm{Cl}$ : $[9.1 ; 13.0], p=0.001)$. In the septic group all studies except one showed EVLWI values above the limit of $7 \mathrm{ml} / \mathrm{kg}(20 / 21)$, whereas 9 of the 19 studies including surgical patients gave the normal values of $3-7 \mathrm{ml} / \mathrm{kg}$.

\section{Discussion}

In this analysis of 138 articles using transpulmonary thermodilution technique, we found a large variance in data for GEDVI and EVLWI, often exceeding the given 'normal' values. Furthermore, data for GEDVI and EVLWI differed significantly between critically ill surgical and septic patients.

For most hemodynamic parameters precise defined values for specific treatment goals are lacking, this applies particularly in critically ill patients. Undoubtedly, the mean arterial pressure (MAP) is the most mentioned and most commonly used parameter in the treatment of circulatory insufficiency. ${ }^{40}$ The Surviving Sepsis Campaign (SCC)

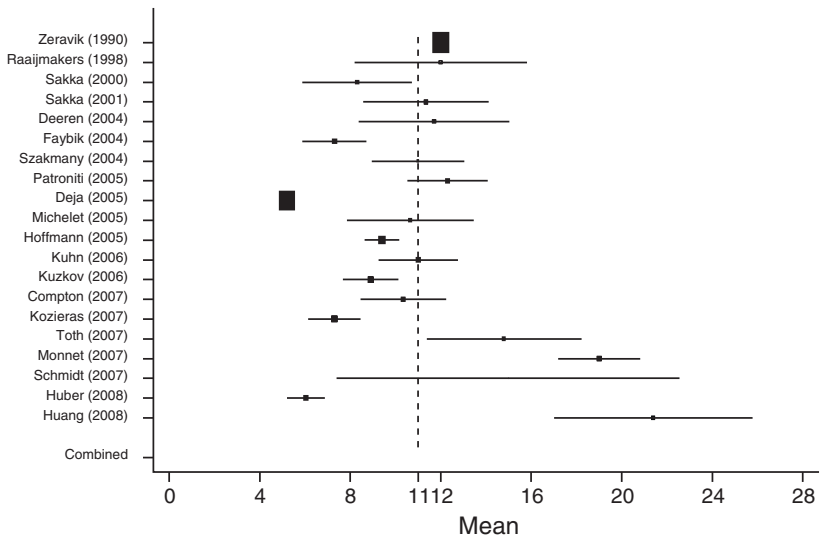

Figure 7 Forest plot of individual study results and pooled mean estimator from a random-effects meta analysis concerning EVLWI data in non-surgical patients (SEP). 
defined a MAP $\geq 65 \mathrm{~mm} \mathrm{Hg}$ and a central venous pressure of $8-12 \mathrm{~mm} \mathrm{Hg}$ to be maintained in septic patients. ${ }^{41}$ But in fact these treatment goals achieve surprisingly low support from other relevant studies. A more critical look at the parameters for preload monitoring shows that there is actually more evidence for the use of volumetric parameters, i.e. GEDVI or left ventricular end diastolic area, and their use in critically ill patients than for filling pressures. ${ }^{42,43}$

In the present literature analysis $60 \%$ of the studies that included surgical patients (SURG group) showed values of GEDVI within the reported normal range of $680-800 \mathrm{ml} / \mathrm{m}^{2}$. In the remaining studies data were below the lower range of $680 \mathrm{ml} / \mathrm{m}^{2}$ regardless the timing of measurement and the type of operation performed.

The normal value of GEDVI was exceeded more often in the critically ill septic patient group: $30 \%$ of the studies gave values above the upper limit of $800 \mathrm{ml} / \mathrm{m}^{2}$. The difference of a GEDVI of $94 \mathrm{ml} / \mathrm{m}^{2}$ between subgroup analysis between the surgical and septic patients is notable, and in the present meta-analysis this difference reached statistical significance. A high percentage of patients with sepsis show acute and reversible left ventricular dilation resulting in systolic left ventricular dysfunction. ${ }^{44}$ This acute dilatation in early sepsis and the need for a higher preload volume to maintain sufficient circulation is most probably reflected in these higher values of GEDVI in the group of non-surgical patients. Thus, the proposed range of normal values may not be appropriate in these critically ill patients. It needs to be considered that the given values were based on cardiopulmonary healthy patients and therefore may not be applicable for septic patients, given the high probability that septic patients need a higher GEDVI to optimize cardiac function. Patients' optimal preload, as expressed by GEDVI, varies between patients' demographic data, underlying type and severity of disease. Therefore an abnormal GEDVI may be satisfactory for one patient, and a normal GEDVI may be misleading for non-optimal cardiac preload.

This moreover stresses the need to individually determine the patient's optimal preload volume when using volumetric parameters of preload to guide therapy. ${ }^{45}$ This can either be done by repetitive volume challenges for determining the patients' ideal cardiac preload, as already proposed ${ }^{46}$; however, this may potentially lead to repetitive, unnecessary and potentially harmful volume application in patients who are not volume responsive. ${ }^{47}$ Continuous dynamic indicators of preload such as left ventricular stroke volume variation or arterial pulse pressure variation can help overcome this dilemma, but only in patients on controlled mechanical ventilation without significant arrhythmias. ${ }^{48}$

For EVLWI, normal values of $3-7 \mathrm{ml} / \mathrm{kg}$ are proposed. Interestingly, only $50 \%$ of the studies in the surgical patient group had values within this normal range. The other $50 \%$ were above the upper limit of $7 \mathrm{ml} / \mathrm{kg}$. Thus, even in this population of surgical patients without long-term intensive care treatment and supposedly without clinically relevant pulmonary edema half of the EVLWI values exceeded the proposed normal value. This finding is noteworthy as it may point towards potential fluid overload for a significant portion of surgical patients. However in the studies including predominantly sepsis patients all mean values for EVLWI were above this upper limit of $7 \mathrm{ml} / \mathrm{kg}$. These studies also revealed a significantly higher EVLWI when compared to the studies performed in surgical patients. This difference is expected, because mechanically ventilated patients in intensive care units suffering from systemic inflammation frequently demonstrate changes in pulmonary permeability. ${ }^{49}$ Therefore the upper limit for EVLWI of $7 \mathrm{ml} / \mathrm{kg}$ almost always exceeded in critically ill patients. This may lead to the concept that maybe the established ideal goal of $7 \mathrm{ml} / \mathrm{kg}$ is too conservative, and perhaps leads to potentially harmful fluid restriction in patients with impaired organ perfusion. Although it is doubtful that patients will remain under resuscitated initially because of a low EVLWI, a high EVLWI above $10-12 \mathrm{ml} / \mathrm{kg}$ remains a reasonable trigger to start late conservative fluid management or late goal directed fluid removal as was recently shown. ${ }^{24,50}$ This holds true particularly when evaluating the increasing evidence that the level of EVLWI correlates with outcome in critically ill patients, promoting the definition of therapeutic goals in this group of patients. However, these goals should then be in line with these findings. Sakka et al. reported a significant increase in mortality in patients with severe sepsis, when EVLWI exceeded $14 \mathrm{ml} / \mathrm{kg} .{ }^{25}$ Thus, for patients with sepsis, values of up to $10-12 \mathrm{ml} / \mathrm{kg}$ may be tolerable, although more data are needed in this regard. ${ }^{22,51}$ Just recently, Phillips et al. showed in critically ill patients the prognostic value of a rise in EVLWI to predict acute lung injury. They also suggested of a trigger point of not less than $10 \mathrm{ml} / \mathrm{kg}$. ${ }^{52,53}$ Therefore treatment goals of $3-7 \mathrm{ml} / \mathrm{kg}$ as proposed as the normal values may not be appropriate in particular in this group of patients. In summary however, combining measurements of GEDVI and EVLWI with volume loading enables balanced volume therapy, i.e. optimized stroke volume and fluid overload avoidance.

Furthermore, in surgical patients in whom duration of ventilation is normally shorter than in patients admitted to the intensive care unit with severe sepsis, half of the studies included in the present data analysis described values of EVLWI above the upper limit of normal EVLWI of $7 \mathrm{ml} / \mathrm{kg}$. This might be explained by perioperative stress and inflammation due to the surgical procedure, but in patients lacking pulmonary alterations it remains notable. This also points towards the fact that the proposed normal range for EVLWI seems only suitable for healthy volunteers and are hardly ever seen in critically ill patients or in patients undergoing moderate to major surgical procedures. These assumptions were confirmed by Tagami et al. in a human autopsy study where they defined a normal EVLWI value of $7.4 \pm 3.3 \mathrm{ml} / \mathrm{kg}$, already slightly above the given normal values of $3-7 \mathrm{ml} / \mathrm{kg} .^{18}$

Several limitations to the present data analysis need to be highlighted. We included all studies found by an extended literature search which documented GEDVI and/or EVLWI and which could be allocated to either a group of surgical patient's monitored perioperatively or to a group of nonsurgical, septic patients. Even though most studies could clearly be assigned to either patient group, definition of these groups was performed arbitrarily, and contamination cannot be ruled out. More subgroups, such as burn patients, could have been created, but none would have obtained a statistically relevant number of patients. Heterogeneity of patients between studies, number of patients per study, timing and number of measurements performed, treatment of patients such as use of vasopressors, inotropes or fluid 
bolus, as well as type of operation or cause of sepsis may also limit the conclusions of this study. Due to the high heterogeneity our results have to be interpreted with caution, but we believe that the statistical significance reached between both groups helps to integrate the data into the clinical management of such patients. We were not able to obtain individual data to re-analyze different thresholds for EVLWI or GEDVI in relation to outcome, nor were we able to calculate corrected GEDVI according to the global ejection fraction (GEF) since this recently has been shown to correlate better with the true preload status especially in patients with low GEF and high GEDVI. ${ }^{54}$

\section{Conclusions}

We conclude that the published values for GEDVI and hemodynamics derived by transcardiopulmonary thermodilution may be misleading under certain clinical circumstances. The proposed values are based on normal values for healthy volunteers and are therefore not directly applicable for critically ill patients. Septic cardiac impairment, i.e. ventricular dilation may be part of the reason why cardiac filling volumes (GEDVI) are often elevated in septic patients. We assume that an individual volume loading approach would be more likely to optimize cardiac preload, even though the actual GEDVI may often be above the upper limit of given values. Our findings show significant differences in GEDVI between surgical and septic patients underlining this assumption.

The normal values given for EVLWI are unlikely to be found in perioperative surgical patients and are almost never seen in critically ill patients with sepsis. Using the proposed normal values of EVLWI as therapeutic targets for septic patients seems therefore questionable, and modifications oriented to values associated with decreased patients' outcome would appear be more reasonable.

\section{Conflict of interest}

Daniel A. Reuter and Manu LNG Malbrain are members of the Pulsion Medical advisory board (Pulsion Medical Systems, Munich, Germany).

\section{References}

1. Rivers E, Nguyen B, Havstad S, Ressler J, Muzzin A, Knoblich B, et al. Early goal-directed therapy in the treatment of severe sepsis and septic shock. N Engl J Med. 2001;345:1368-77.

2. Hamilton MA, Cecconi M, Rhodes A. A systematic review and meta-analysis on the use of preemptive hemodynamic intervention to improve postoperative outcomes in moderate and high-risk surgical patients. Anesth Analg. 2011;112:1392-402.

3. Hata JS, Stotts C, Shelsky C, Bayman EO, Frazier A, Wang J, et al. Reduced mortality with noninvasive hemodynamic monitoring of shock. J Crit Care. 2010:31.

4. Michard F, Teboul JL. Predicting fluid responsiveness in ICU patients: a critical analysis of the evidence. Chest. 2002;121:2000-8.

5. Robotham JL, Takata M, Berman M, Harasawa Y. Ejection fraction revisited. Anesthesiology. 1991;74:172-83.
6. Michard F, Alaya S, Zarka V, Bahloul M, Richard C, Teboul JL. Global end-diastolic volume as an indicator of cardiac preload in patients with septic shock. Chest. 2003;124:1900-8.

7. Reuter DA, Huang C, Edrich T, Shernan SK, Eltzschig HK. Cardiac output monitoring using indicator-dilution techniques: basics, limits, and perspectives. Anesth Analg. 2010;110:799-811.

8. Malbrain ML, De Potter P, Deeren D. Cost-effectiveness of minimally invasive hemodynamic monitoring. Yearb Intensive Care Emerg Med. 2005:603-18

9. Jonas M, Tanser S. Lithium dilution measurement of cardiac output and arterial pulse waveform analysis: an indicator dilution calibrated beat-by-beat system for continuous estimation of cardiac output. Curr Opin Crit Care. 2002;8: 257-61.

10. Bendjelid K, Giraud R, Siegenthaler N, Michard F. Validation of a new transpulmonary thermodilution system to assess global end-diastolic volume and extra-vascular lung water. Crit Care. 2010;14:R209.

11. Chappell D, Jacob M, Hofmann-Kiefer K, Conzen P, Rehm M. A rational approach to perioperative fluid management. Anesthesiology. 2008;109:723-40.

12. Eisenberg PR, Jaffe AS, Schuster DP. Clinical evaluation compared to pulmonary artery catheterization in the hemodynamic assessment of critically ill patients. Crit Care Med. 1984; 12:549-53.

13. Deeren DH, Dits H, Daelemans R, Malbrain ML. Effect of pleural fluid on the measurement of extravascular lung water by single transpulmonary thermodilution. Clin Intensive Care. 2004;15:119-22.

14. Patroniti N, Bellani G, Maggioni E, Manfio A, Marcora B, Pesenti A. Measurement of pulmonary edema in patients with acute respiratory distress syndrome. Crit Care Med. 2005;33: 2547-54.

15. Michard F. Bedside assessment of extravascular lung water by dilution methods: temptations and pitfalls. Crit Care Med. 2007;35:1186-92.

16. Neumann P. Extravascular lung water and intrathoracic blood volume: double versus single indicator dilution technique. Intensive Care Med. 1999;25:216-9.

17. Sakka SG, Rühl CC, Pfeiffer UJ, Beale R, McLuckie A, Reinhart $\mathrm{K}$, et al. Assessment of cardiac preload and extravascular lung water by single transpulmonary thermodilution. Intensive Care Med. 2000;26:180-7.

18. Tagami T, Kushimoto S, Yamamoto Y, Atsumi T, Tosa R, Matsuda $\mathrm{K}$, et al. Validation of extravascular lung water measurement by single transpulmonary thermodilution: human autopsy study. Crit Care. 2010;14:162.

19. Kuzkov VV, Suborov EV, Kirov MY, Waerhaug K, Mortensen $\mathrm{R}$, Kuklin VN, et al. Radiographic lung density assessed by computed tomography is associated with extravascular lung water content. Acta Anaesthesiol Scand. 2010;54: 1018-26.

20. Kirov MY, Kuzkov VV, Kuklin VN, Waerhaug K, Bjertnaes LJ. Extravascular lung water assessed by transpulmonary single thermodilution and postmortem gravimetry in sheep. Crit Care. 2004;8:R451-8.

21. Katzenelson R, Perel A, Berkenstadt H, Preisman S, Kogan S, Sternik $L$, et al. Accuracy of transpulmonary thermodilution versus gravimetric measurement of extravascular lung water. Crit Care Med. 2004;32:1550-4.

22. Martin GS, Eaton S, Mealer M, Moss M. Extravascular lung water in patients with severe sepsis: a prospective cohort study. Crit Care. 2005:74-82.

23. Schuller D, Mitchell JP, Calandrino FS, Schuster DP. Fluid balance during pulmonary edema. Is fluid gain a marker or a cause of poor outcome? Chest. 1991;100:1068-75.

24. Cordemans C, De laet I, Van Regenmortel N, Schoonheydt K, Dits $H$, Martin $G$, et al. Aiming for negative fluid balance in 
patients with acute lung injury and increased intra-abdominal pressure: a pilot study looking at the effects of PAL-treatment. Ann Intensive Care. in press.

25. Sakka SG, Klein M, Reinhart K, Meier-Hellmann A. Prognostic value of extravascular lung water in critically ill patients. Chest. 2002;122:2080-6.

26. Goepfert MS, Reuter DA, Akyol D, Lamm P, Kilger E, Goetz AE. Goal-directed fluid management reduces vasopressor and catecholamine use in cardiac surgery patients. Intensive Care Med. 2007;33:96-103.

27. Carl M, Alms A, Braun J, Dongas A, Erb J, Goetz A, et al. S3 guidelines for intensive care in cardiac surgery patients: hemodynamic monitoring and cardiocirculary system. Ger Med Sci. 2010;8:12.

28. Kirov MY, Kuzkov VV, Molnar Z. Perioperative haemodynamic therapy. Curr Opin Crit Care. 2010;16:384-92.

29. Wolf S, Rieß A, Landscheidt JF, Lumenta CB, Friederich $P$, Schürer L. Global end-diastolic volume acquired by transpulmonary thermodilution depends on age and gender in awake and spontaneously breathing patients. Crit Care. 2009;13:202.

30. van Houwelingen HC, Arends LR, Stijnen T. Advanced methods in meta-analysis: multivariate approach and meta-regression. Stat Med. 2002;21:589-624.

31. Buhre W, Bendyk K, Weyland A, Kazmaier S, Schmidt M, Mursch $\mathrm{K}$, et al. Assessment of intrathoracic blood volume. Anaesthesist. 1998;47:51-3.

32. Preisman S, Kogan S, Berkenstadt H, Perel A. Predicting fluid responsiveness in patients undergoing cardiac surgery: functional haemodynamic parameters including the Respiratory Systolic Variation Test and static preload indicators. $\mathrm{Br} \mathrm{J}$ Anaesth. 2005;95:746-55.

33. Toth I, Leiner T, Mikor A, Szakmany T, Bogar L, Molnar Z. Hemodynamic and respiratory changes during lung recruitment and descending optimal positive end-expiratory pressure titration in patients with acute respiratory distress syndrome. Crit Care Med. 2007;35.

34. Monnet X, Anguel N, Osman D, Hamzaoui O, Richard C, Teboul JL. Assessing pulmonary permeability by transpulmonary thermodilution allows differentiation of hydrostatic pulmonary edema from ALI/ARDS. Intensive Care Med. 2007;33:448-53.

35. von Spiegel T, Giannaris S, Wietasch GJ, Schroeder S, Buhre W, Schorn B, et al. Anesthesiology. 2002;96:827-34.

36. Licker M, Tschopp JM, Robert J, Frey JG, Diaper J, Ellenberger C. Aerosolized salbutamol accelerates the resolution of pulmonary edema after lung resection. Chest. 2008;133:845-52.

37. Hüter L, Schwarzkopf K, Preussler NP, Gaser E, Schubert $\mathrm{H}$, Karzai W. Measuring cardiac output in one-lung ventilation: a comparison of pulmonary artery and transpulmonary aortic measurements in pigs. J Cardiothorac Vasc Anesth. 2004;18:190-3.

38. Roch A, Michelet P, D'journo B, Brousse D, Blayac D, Lambert D, et al. Accuracy and limits of transpulmonary dilution methods in estimating extravascular lung water after pneumonectomy. Chest. 2005;128:927-33.

39. Deja M, Hildebrandt B, Ahlers O, Riess H, Wust P, Gerlach $\mathrm{H}$, et al. Goal-directed therapy of cardiac preload in induced whole-body hyperthermia. Chest. 2005;128:580-6.
40. Kastrup M, Markewitz A, Spies C, Carl M, Erb J, Grosse J, et al. Current practice of hemodynamic monitoring and vasopressor and inotropic therapy in post-operative cardiac surgery patients in Germany: results from a postal survey. Acta Anaesthesiol Scand. 2007;51:347-58.

41. Dellinger RP, Levy MM, Carlet JM, Bion J, Parker MM, Jaeschke $\mathrm{R}$, et al. Surviving sepsis campaign: international guidelines for management of severe sepsis and septic shock. Intensive Care Med. 2008;34:17-60.

42. Kumar A, Anel R, Bunnell E, Habet K, Zanotti S, Marshall S, et al. Pulmonary artery occlusion pressure and central venous pressure fail to predict ventricular filling volume, cardiac performance, or the response to volume infusion in normal subjects. Crit Care Med. 2004;32:691-9.

43. Swenson JD, Bull D, Stringham J. Subjective assessment of left ventricular preload using transesophageal echocardiography: corresponding pulmonary artery occlusion pressures. J Cardiothorac Vasc Anesth. 2001;15:580-3.

44. Bouhemad B, Nicolas-Robin A, Arbelot C, Arthaud M, Féger F, Rouby JJ. Acute left ventricular dilatation and shock-induced myocardial dysfunction. Crit Care Med. 2009;37:441-7.

45. Michard F, Reuter DA. Assessing cardiac preload or fluid responsiveness? It depends on the question we want to answer. Intensive Care Med. 2003;29:352-60.

46. Vincent JL, Weil MH. Fluid challenge revisited. Crit Care Med. 2006;34:1333-7.

47. Maitland K, Kiguli S, Opoka RO, Engoru C, Olupot-Olupot $\mathrm{P}$, Akech SO, et al. Mortality after fluid bolus in African children with severe infection. N Engl J Med. 2011;364: 2483-95.

48. Marik PE, Cavallazzi R, Vasu T, Hirani A. Dynamic changes in arterial waveform derived variables and fluid responsiveness in mechanically ventilated patients: a systematic review of the literature. Crit Care Med. 2009;37:2642-7.

49. Vincent JL, Sakr Y, Sprung CL, Ranieri VM, Reinhart K, Gerlach H, et al. Sepsis in European intensive care units: results of the SOAP study; Sepsis Occurrence in Acutely III Patients Investigators. Crit Care Med. 2006;34:344-53.

50. Murphy CV, Schramm GE, Doherty JA, Reichley RM, Gajic $O$, Afessa $B$, et al. The importance of fluid management in acute lung injury secondary to septic shock. Chest. 2009;136: 102-9.

51. Sturm JA. Entwicklung und Bedeutung der Lungenwassermessung in Klinik und Experiment. In: Bergmann $\mathrm{H}$, Gilly $\mathrm{H}$, Steinbereithner $\mathrm{K}$, editors. Beiträge zur Anästhesiologie und Intensivmedizin. Wien, Austria: Verlag Wilhelm Maudrich; 1984. p. 15-39.

52. LeTourneau JL, Pinney J, Phillips CR. Extravascular lung water predicts progression to acute lung injury in patients with increased risk. Crit Care Med. 2011 Oct 27.

53. Michard F, Fernandez-Mondejar E, Kirov M, Malbrain MLNG, Tagami T. A new and simple definition for acute lung injury. Crit Care Med. in press.

54. Malbrain ML, De Potter TJ, Dits H, Reuter DA. Global and right ventricular end-diastolic volumes correlate better with preload after correction for ejection fraction. Acta Anaesthesiol Scand. 2010;54:622-31. 